\title{
Changing patterns of work
}

\author{
Peter Doyle
}

This is the third in a series of articles which explore the new deal on junior doctors' hours of work and explain how it will be implemented.
NHS Management

Executive, Department of Health, London W1N 5TB Peter Doyle, FRCSED, senior medical officer, Medical Manpower and Education Division

BMF 1991;303:982-4
Throughout the history of the NHS out of hours emergency cover has been provided primarily by doctors in training working on call rotas. Recently, this practice has given increasing grounds for concern, partly because of the implications for training grade manpower, but also because of the problems associated with having to work for long periods of duty.

In 1948 the Spens report was instrumental in establishing the staffing structure of hospitals in the new National Health Service. ${ }^{1}$ Almost ever since the NHS and the medical profession have been wrestling with the problem of providing an acceptable hospital career structure, while at the same time employing enough non-consultant staff to provide adequate out of hours emergency cover.

In 1986 Hospital Medical Staffing-Achieving a Balance was agreed, ${ }^{2}$ followed shortly afterwards by Achieving a Balance-Plan for Action. ${ }^{3}$ These agreements set out an ambitious 10 year programme to reform the hospital career structure. Essentially, the numbers of doctors in the two main training grades, senior registrar and career registrar (those registrars with the right to make a career in the United Kingdom) in each specialty would be carefully controlled by the Joint Planning Advisory Committee (JPAC) in relation to career opportunities. It was acknowledged at the time that the provision of " 24 -hour emergency cover of satisfactory clinical standard in acute units" would not be easy and might require some redistribution of training posts and cross cover between units.

By the autumn of 1989 the JPAC had completed initial scrutinies of senior registrars and career registrars in all the medical specialties.

At about the same time regional health authorities submitted to the Department of Health reports on the numbers of non-consultant staff available to provide emergency cover and the hours they were working. These showed that something like a third of doctors in training were still working a one in three rota or worse. Even so, the emergency cover was thin in some units. The reports argued for increases in training grade doctors to improve unsatisfactory rotas. It was estimated from the JPAC figures and the reports from the regions that to improve all unsatisfactory rotas sufficiently to reduce hours of work to acceptable levels could require as much as 2500 additional doctors in the training grades. Such an increase would put an end to prospects of an acceptable career structure.

There is, however, more to the problem of hours of work than the manpower equation. The interim report by Robin Dowie on junior doctors' hours painted a very graphic picture of the problems associated with the long continuous hours worked by some doctors in training. ${ }^{4}$ Concern was being expressed about the possible detrimental effects of such hours on the doctors themselves and the consequent implications for patients under their care. ${ }^{56}$

\section{ON CALL ROTAS}

Examination of a rota shows several basic problems associated with on call rotas (fig 1). The normal duty period during the week for a standard one in four rota is a minimum of 32 hours, often made longer by early starts or late finishes. Weekend duties can be up to 80 hours and total hours for week one, which includes the weekend on, can be as long as 120 . Average contracted hours are long, 72 a week (assuming that cover for colleagues on leave-prospective cover-is excluded), because the doctor works a normal 40 hour week with on call duties added. Improving the rota from one in three to one in four or one in five only reduces the frequency at which long hours are worked. It does nothing for the long periods of duty themselves.

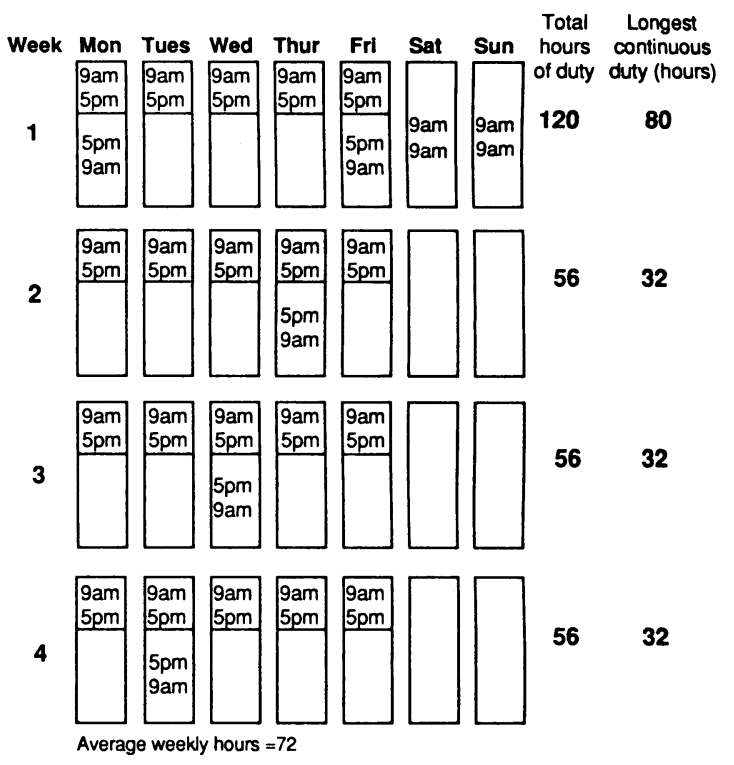

FIG 1-One in four rotas

Weekend duties can be reduced by splitting the weekend, but the only way to reduce the long continuous periods of duty is to give time off after a night on call. This can reduce duty hours during the week to 24 , but, even with a split weekend, doctors may still find themselves working continuously for up to 48 hours at the weekend. Also there will be one doctor fewer on duty during the day.

Such long continuous periods of duty are acceptable if the doctor is on call only for occasional emergencies, but are no longer satisfactory where the doctor is expected to be up, working, and making important clinical judgments. Some means has to be found to reduce periods of duty to lengths commensurate with the volume and intensity of the workload.

\section{Shifts: only practical solution}

The only practical means of reducing the long continuous periods of duty is the introduction of some sort of shift system. Shift systems have been in use in some accident and emergency departments for many years. More recently they have been tried in other acute units. ${ }^{78}$ Two basic types of shift system can be used in medical practice, full shifts and partial shifts.

\section{FULL SHIFTS}

Figure 2 illustrates a standard shift system for four doctors based on the type in common use in some industries but adapted for use in hospital by allowing 
an hour's overlap between shifts. There is a dramatic reduction, not just in the average hours worked but in the other difficulties associated with on call rotas. The longest continuous period of duty is reduced to 13 hours and the longest week ( 71 hours) is shorter than the average week for the equivalent four person on call rota.

Only three of the doctors would be required to provide 24 hour cover. Week four could be allowed almost entirely as off duty reducing average hours even further. Alternatively it could be used to provide extra cover during parts of the day when the workload was high or dedicated to specific training activities. It is possible, therefore, to run a three person full shift. But duties become more onerous and average hours would exceed the controls set out in funior Doctors. The New Deal..$^{9}$ Although not recommended for prolonged use, a three person shift can be used to cover for short periods in an emergency. With more than four doctors shift systems become much more flexible.

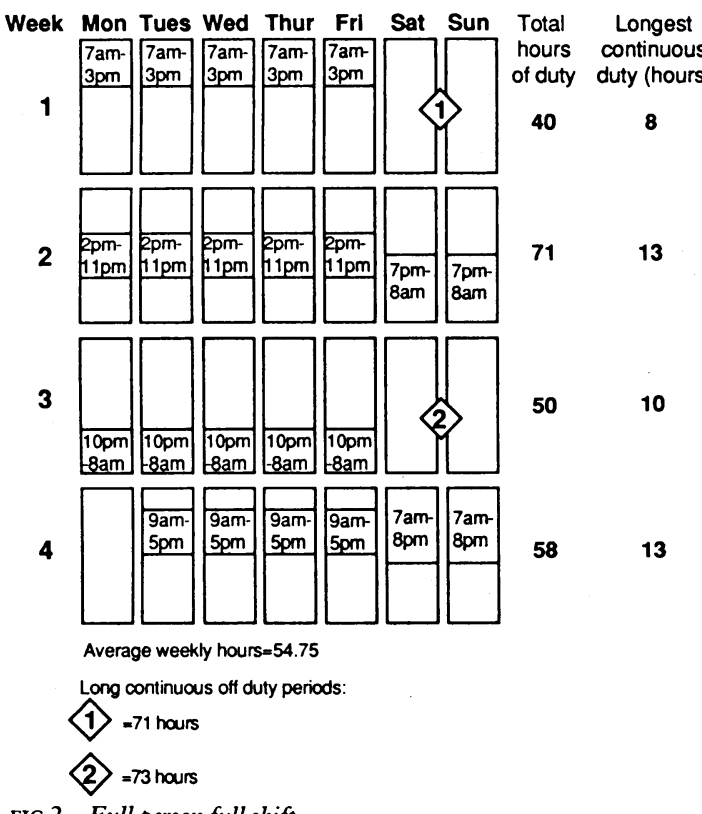

FIG 2-Full person full shift

\section{PARTIAL SHIFTS}

Full shift systems are best suited to situations where the workload is intensive and potentially fairly evenly spread over the 24 hours such as in accident and emergency or intensive care units. Most medical specialties have a large routine workload during the day. It is important that doctors in training participate as fully as possible in the routine work as well as seeing the emergencies. Here a partial shift system is more appropriate. In a four doctor partial shift three of the doctors are on duty during the day and only one moves on to a different shift, normally nights, every four weeks (fig 3). Again, the longest shift is 13 hours and the average hours a week, although not cut as dramatically as in a full shift, show a marked reduction from the comparable on call rota. Overlaps are included to allow for adequate handover. A three doctor partial shift is theoretically possible but not advocated except to cover short term difficulties. With more than four doctors flexibility increases.

One of the most important features of shift systems is their inherent flexibility. For example, if the workload on nights is relatively low after midnight the night shift can be lengthened to 16 hours on the basis that the duty is not onerous and the doctor on duty is likely to get several hours' rest. Shift lengths can be adapted to accommodate early starts and late finishes, and can be altered over time to take account of changes in the volume or distribution of the workload. It is likely
Week Mon Tues Wed Thur Fri Sat Sun Total Longest $\left.\left.\left.\begin{array}{l}7 \mathrm{am} \\ 5 \mathrm{pm}\end{array}\right] \begin{array}{l}7 \mathrm{am} \\ 5 \mathrm{pm}\end{array}\right] \begin{array}{l}7 \mathrm{am} \\ 5 \mathrm{pm}\end{array}\right] \begin{aligned} & 7 \mathrm{am} \\ & 5 \mathrm{pm}\end{aligned} \square$ of duty duty (hours) $5 \mathrm{pm} 5 \mathrm{pm} 5 \mathrm{pm}$

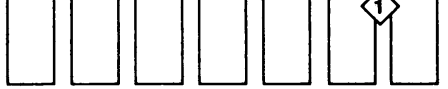

5010

2

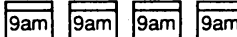

$5 \mathrm{pm} 5 \mathrm{pm}$
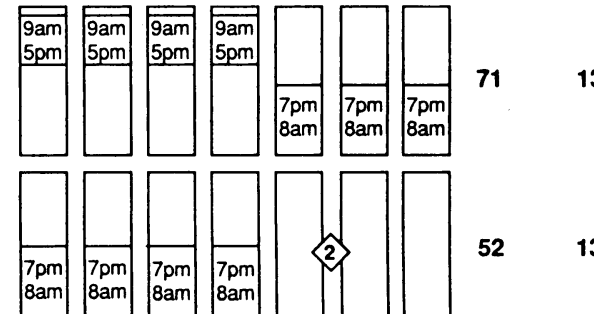

13

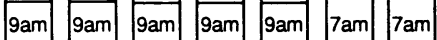

$8 \mathrm{pm} 8 \mathrm{pm} 8 \mathrm{pm} 8 \mathrm{pm} \quad 8 \mathrm{pm} 8 \mathrm{pm}$

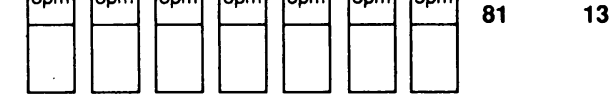

Average weekly hours $=63.5$

Long continuous off duty periods:

1) 64 hours

2. 73 hours

FIG 3-Four person partial shift

that when shifts are first introduced they will need to be modified to obtain the optimum pattern to meet local needs.

Another advantage is that part time staff can easily be integrated into the shift pattern (fig 4). Whether doctors are training or employed on a part time basis they usually wish to work to a fairly set pattern which meets their other commitments. This has proved difficult to arrange with conventional on call rotas. Shifts offer the opportunity to provide a fixed set of duty periods which provide the range of experience required for training and enable the other doctors on the shift pattern to reduce their hours even further.

\section{Implications of shifts}

The major implications of the introduction of shift

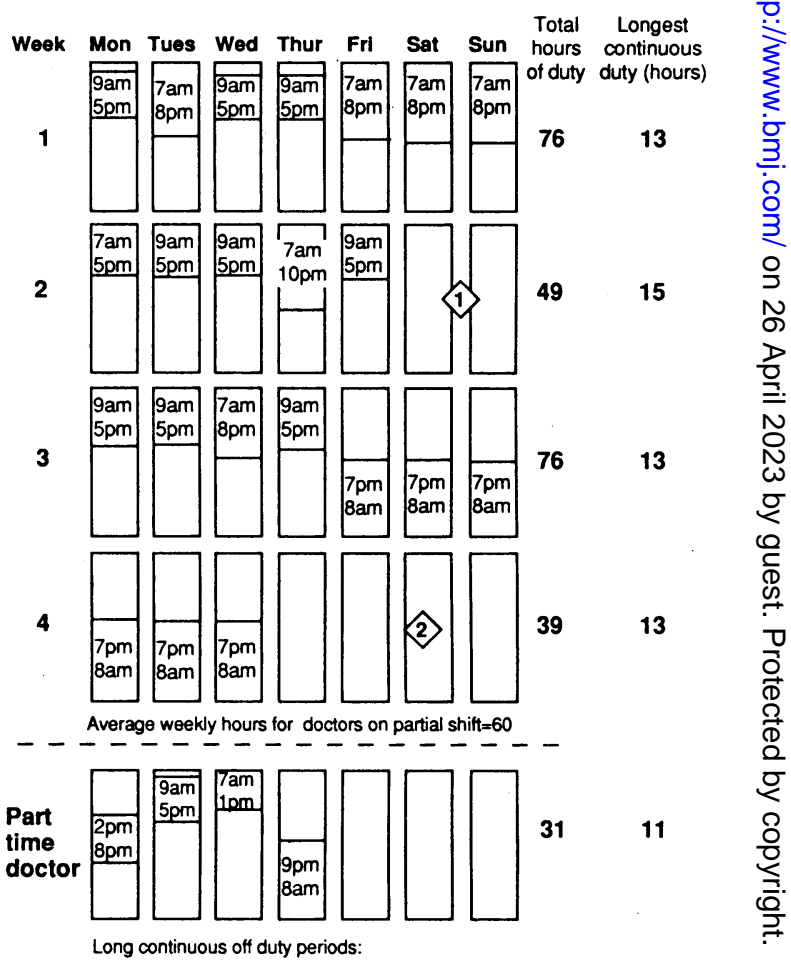

(1) 64 hours

(2) 97 hours

FIG 4-Partial shift and part timer 
systems are for manpower, the organisation of clinical services, and teaching.

\section{MANPOWER}

Shift systems reduce the number of doctors on duty during the normal working day (similar to giving time off after a night on call). A partial shift will reduce the numbers by one doctor and a full shift may reduce the number of doctors available during the day to only one or possibly two. The work which would have been done by doctors on a rota will have to be undertaken by someone else. Much depends on the nature of the work done. There is evidence that for house officers and senior house officers at least a considerable proportion of their time on duty is devoted to tasks that could be done by non-medical staff. ${ }^{10} 11$ The guidance which forms part of the new deal explains how this type of work might be undertaken and by whom. ${ }^{9}$

\section{The major implications of the introduction of shift systems are for manpower, the organisation of clinical services, and teaching.}

If there is more daytime medical work than the remaining medical staff (relieved of non-medical duties) can manage additional medical staff will have to be appointed. Employing medical staff to work predominantly during the normal working week should prove relatively easy. Such posts are ideal for long term employment and therefore for career grade staff such as consultants and staff grades (and possibly on a part time basis, hospital practitioners). Thus the manpower demand created by a move to shift systems is for career grade not training grade doctors. This is a fundamental and important difference from the demand for additional training grade doctors that arises from improving rotas. A move to increased use of shift systems will improve the career balance and could give a boost to Achieving a Balance.

It has to be recognised, however, that shift systems work best with four or more doctors in the shift pattern. How can this be achieved? Increased use of cross cover will be important especially at basic level. Rationalisation of services between sites, and in due course some rationalisation of acute sites will make a contribution. Staff grade doctors can, on their current terms and conditions of service, participate in shift systems as they will be working substantially the whole of the time they are on duty. Another important consideration will be the distribution of training posts both within and between regions.

It may also have to be accepted that in some units, where the workload is low, continuous intermediate cover will not be possible. As is already the case, consultants may have to continue to be on call with only a relatively inexperienced senior house officer (colleges have given guidance on this in The New Deal.) If there is a registrar or other intermediate grade on the unit he or she may still do perhaps one in four nights on call to comply with the hours' controls, but there will be no intermediate grade on call on the other three nights.

\section{ORGANISATION OF CLINICAL SERVICES}

A major consideration for clinical staff is the way they are organised. In units where the firm structure predominates working arrangements will be more difficult if one member of the firm is on nights from time to time. In contrast those units organised on the basis of a specialty team will be able to adapt to the new working arrangements relatively easily. Whatever the structure of the clinical unit the introduction of new patterns of work will require reappraisal of the way all staff work. It is important to ensure that the change does not relieve the problem for one grade by making the life of others more difficult. For instance, the timing of ward rounds could help make hand over periods more effective and improve continuity of care. Annual and study leave have to be carefully timetabled to reduce disruption to working arrangements.

It is likely that there will be a move towards more specialty team working. This type of organisation already offers advantages in being able to match available medical staff to the workload. Consultants can arrange in advance to have the level of support appropriate to a particular session. Training grade staff can be directed preferentially to those duties of most value for their training. They have more opportunity to compare different clinical methods and are not dependent on one consultant for a reference. As has already been suggested, it is easier to accommodate part time staff whether in a training or career grade.

\section{TEACHING}

With a move to more shift working, assembling all staff for audit meetings, teaching rounds, etc, will be more difficult and thought will have to be given to how teaching can be delivered effectively. One important opportunity will be the ability to dedicate certain shifts to specific training opportunities and activities. Above all, reducing hours of work will mean that doctors in training will be sufficiently rested to ensure that time spent receiving formal teaching, or in private study, is more effective.

The new deal on juniors' hours has set controls on the hours that can be worked by doctors in training. At the same time it has introduced a wide range of working practices which, while not new, have so far had only limited application. I have tried to show why the greater use of shift systems is essential, not just to reduce hours of work overall, but to tailor those hours to match the wide diversity of medical work now found in hospital practice. It will take time and a great deal of thought and experimentation to get the best out of these arrangements. Their very flexibility allows, if necessary, modification as needs change. Furthermore, all this can be achieved without sacrificing, but actually improving, the hospital medical career structure and the quality of patient care.

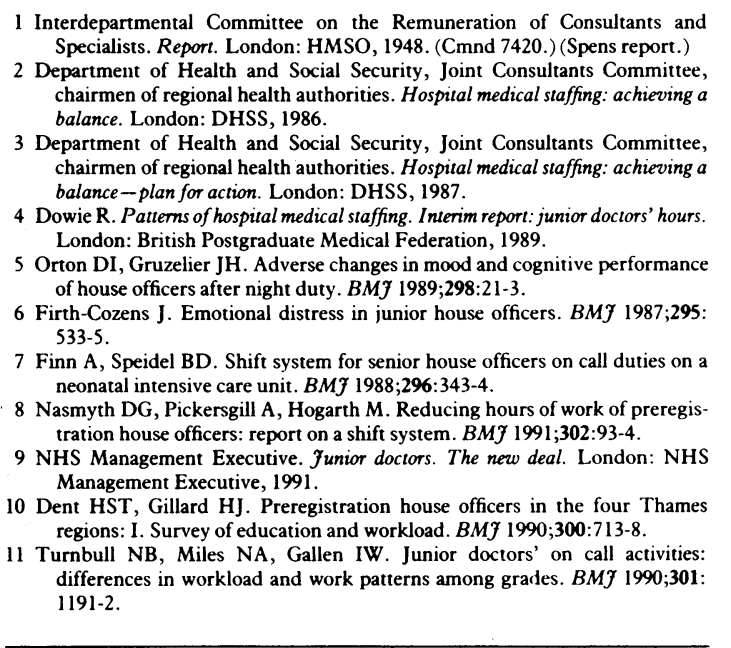

\section{Correction}

\section{The young patient with claudication}

An editorial error occurred in this article by MrD T Reilly and Mr John $\mathrm{H} N$ Wolfe (5 October, $p$ 845). The lymphogram at the bottom of $p 845$ should not have appeared in this article. It is a normal isotope lymphogram of legs and pelvis and does not show popliteal aneurysm as published. 